\title{
A UNIVERSITY'S EXPERIENCE ON THE DEVELOPMENT OF ENTERPRISE INFORMATION SYSTEMS CURRICULUM
}

\author{
Paul J. Kovacs, Robert Morris University,kovacs@rmu.edu \\ John Turchek, Robert Morris University, turchek@rmu.edu \\ DavidWood, Robert Morris University,wood@rmu.edu \\ Michael Bitner, Robert Morris University, mbitner@outlook.com
}

\begin{abstract}
In this era of Web-centric languages such as .NET and Java for modern programming needs such as mobile apps and the Web, many university Computer and Information Systems departments have discontinued teaching the COBOL language. However, even though some noncore COBOL applications are moving off the mainframe to distributed computing platforms, those COBOL batch and transaction processing programs on the mainframe represent an enormous investment. In a recent Computerworld survey, of 357 IT professionals, $46 \%$ of the respondents said they are already noticing a Cobol programmer shortage, while 50\% said the average age of their Cobol staff is 45 or older and 22\% said the age is 55 or older [10]. This paper explains what Information Technology managers from industry, IBM, and one University Computer and Information Systems department is doing to manage the loss of mainframe programming skills, with a specific focus on the Enterprise Information System programing skill set of COBOL programmers.
\end{abstract}

Keywords: COBOL Programming, IBM Enterprise Information Systems, IBM mainframe, CIS Curriculum

\section{INTRODUCTION}

The mainframe computer has always been the IT industry's leading platform for bulk data processing such as transaction processing, as well as consolidated and secure data serving, and supporting enterprise-wide applications.. However, in this era of Web-centric languages such as .NET and Java for modern programming needs such as mobile apps and the Web, many university Computer and Information Systems departments have deemphasized the mainframe and discontinued teaching the COBOL language. This is true even though some noncore COBOL applications are migrating from the mainframe to distributed computing platforms, those COBOL batch and transaction processing programs on the mainframe represent an enormous investment. According to analyst estimates, $60-80$ percent of the world`s enterprises still rely on COBOL to run their business [3]. There are over 200 billion lines of COBOL code with hundreds being written daily and COBOL programs run almost three quarters of the world's business applications and power almost all global ATM transactions [12]. However, in a recent Computerworld survey of 357 IT professionals, $46 \%$ of the respondents said they are already noticing a Cobol programmer shortage, while $50 \%$ said the average age of their Cobol staff is 45 or older and $22 \%$ said the age is 55 or older [10].

The shortage in regard to the mainframe legacy COBOL skill set can adversely impact an organization since tacit knowledge is lost with an employee's departure. Tacit knowledge refers to unwritten or unspoken knowledge that is not easily articulated, and exists only with the individuals who obtain the knowledge through their experiences [11]. For example, once an engineer leaves an organization, the knowledge that person accumulated from working with different information systems may be lost, and approximately $50 \%$ of the cost of software maintenance is used to recreate this lost knowledge [1]. In addition to employee attrition, other factors relating to and contributing to tacit knowledge loss include lack of documentation from past employees on the mainframe or the programming language and the lack of education of current college students [2].

Educators are continually challenged regarding the scope and content of their curriculums in order to effectively market graduates from their Information Systems (IS) programs. Additionally, Information Systems executives in 


\section{Issues in Information Systems \\ Volume 14, Issue 1, pp.82-88, 2013}

business and industry have similar concerns in relation to the continued need to maintain large-scale COBOL batch and transaction processing operations on mainframes as well as developing new systems.

This paper explains how one University's Computer and Information Systems department has teamed with Information Systems executives in business and industry and IBM to manage the loss of mainframe programming skills, with a specific focus on the Enterprise Information System programing skill set of COBOL programmers.

\section{MAINFRAME EDUCATION AND THE COBOL PROGRAMMER}

The education issue regarding COBOL programmers is currently being addressed by organizations such as Micro Focus and IBM. In 2007, both of these companies began an initiative to have over 300 educational intuitions support mainframe training and providing classes for supported programming languages such as COBOL [8].

In December 2011, IBM announced that over 1,000 schools worldwide are teaching courses for IBM mainframe technology such as the IBM System z Mainframe [5]. The IBM System z Academic Initiative program was created to permit schools to use IBMs' own resources at no cost through IBM cloud delivery model. This delivery model enables schools to expose their students to enterprise systems without the need to purchase or maintain enterprise systems of their own [5].

According to IBM, schools should be teaching students on the mainframe platform for the following reasons:

1. The top 25 of the world's banks runs their business mainframes.

2. Approximately $71 \%$ of the Fortune 500 companies are system $\mathrm{z}$ clients.

3. Out of the top ten global life/health insurance provider, nine process high volume transactions on a mainframe [7].

As of 2012, 28 states in the United States have schools that are investigating or teaching mainframe technologies. Some of the System Z courses related to this research and Enterprise Application Systems include the following.

- An Introduction to the Mainframe - Large Scale Commercial Computing

- An Introduction to the Mainframe - Networking

- An Introduction to the Mainframe - Networking (Audio Version)

- An Introduction to the Mainframe - Security

- An Introduction to the Mainframe - Security (Audio Version)

- An Introduction to the Mainframe - z/OS Basics

- An Introduction to the Mainframe - z/OS Basics (Audio Version)

- An Introduction to the New Mainframe - z/OS Basics (Traditional Chinese)

- An Introduction to the New Mainframe - z/VSE Basics

- COBOL Learning Modules

- Introduction to the COBOL Language

- Teaching Enterprise Systems

\section{IBM University Case Studies}

IBM has conducted case studies of universities associated with the System Z program, at both University of Maryland Eastern Shore (UMES) and the University of Arkansas.

The University of Maryland Eastern Shore started with the university teaming with IBM by hiring an independent industry consultant to form the Enterprise Systems curriculum. The independent consultants approach was to design a curriculum for Computer Science, Engineering, and Information Systems departments. The object was to help design the Enterprise Systems curriculum and form strategic business partnerships with IT companies. In addition to IBM, two multinational financial services corporations were brought in to create a partnership with the university. Some of the challenges include forming an enterprise systems curriculum and training the IT instructors to direct on 


\section{Issues in Information Systems \\ Volume 14, Issue 1, pp.82-88, 2013}

the new curriculum [4]... To assistance in bridging this gap of experience, the University of Maryland Eastern Shore professors and students served a six-month work assignment at the IBM Poughkeepsie lab to help establish the curriculum. Thompson mentioned that "it takes three to four years to fully train a mainframe programmer in their specific environments" [4, $\mathrm{p} 6]$. The training has helped the student reduce the gap for enterprise systems experience by exposing the student to some of the following courses:

- Enterprise Systems

- SOA

- Assembler

- $\mathrm{COBOL}$

The University of Arkansas case study entails how the university has been incorporating enterprise curriculum for the past 10 years. The need for the enterprise curriculum originated because the neighboring business community needed enterprise skills. The business community included organizations such as Wal-Mart, Tyson Foods, Dillard's Department Stores and Fed Ex [6]. The enterprise systems imitative gained momentum in 2007 when IBM donated a System z900, and then in 2012 a System z10 mainframe that included free software and hardware. The curriculum expanded at the university to include three additional classes on Enterprise Resource Planning (ERP). These three classes use SAP ERP on a System z mainframe, which utilizes a DB2 database. The three courses include Integration and Processes, Configuration, and Customization. The enterprise systems program at the University of Arkansas allows graduates of the program a strategic advantage because of the coursework in SAP ERP [6]. This is because "SAP ERP is used by almost all of the Fortune 500 companies" [6, p 3.].

Micro Focus is also involved with universities around the world. The Micro Focus Academic Connections (ACTION) is a program that focuses on assisting universities in teaching COBOL on modern Enterprise technology [9]. The main goals of the ACTION program include the following:

- Taking industry training to universities

- Support universities to meet business demand for IT skills

- Bringing together academic research and enterprise application

- Bridging the gap between academia and industry" [9]

The IBM System z Academic Initiative and the Micro-Focus ACTION programs have formed a partnership to establish courses that supports both mainframe and COBOL.

\section{THE DEVELOPMENT OF ENTERPRISE SYSTEMS CURICULUM IN RMU'S CIS DEPARTMENT}

The Computer and Information Systems Department at Robert Morris University began teaching COBOL and Advanced COBOL in 1974 as required courses in the undergraduate information systems degree program. In 1989, CICS/COBOL, IMS, and DB2 courses were added to the undergraduate program. By 2002, the 15-credit mainframe emphasis slowly began to be de-emphasized in the curriculum as other distributed computing and emerging technology courses were developed. By 2005, the mainframe emphasis had disappeared from the curriculum.

In the Fall semester of 2011, IBM corporation and a consortium of several fortune 500 and smaller corporations in South Western Pennsylvania approached the University with the need to bring back COBOL and other mainframe courses. The consortium was concerned with finding new COBOL programmers, who they expected to be in short supply in the next five to 10 years due to attrition and retirements.

Recognizing the past position of the CIS Department as a major supplier of enterprise systems professionals and the growing demand for new professionals, the department immediately agreed to bring back both COBOL and Advanced COBOL at the undergraduate and graduate levels. Also, an advisory group was formed to help in the curriculum design process (the RMU IBM Regional Planning Group). After six months period of course design, the Enterprise Systems Program was completed and adopted. In the March 2012 meeting of the Regional Planning 


\section{Issues in Information Systems \\ Volume 14, Issue 1, pp.82-88, 2013}

Group, the university was awarded a mainframe computer from the IBM Innovation Center in Dallas to provide dedicated z/OS for instruction purposes. The Enterprise Systems Program was designed to be delivered online or on-ground as part of either a certificate or part of a degree at either the undergraduate or graduate levels. Year one plans were to deliver all of the courses only on-ground.

The five courses in the Enterprise Systems program are as follows:

INFS2130/INFS6130 COBOL Programming ( 3 credits)

This course provides the student an introduction to structured programming through use of the COBOL language. Emphasis is placed on structured programming techniques, logic structures, and modular design; the use of design tools such as flowcharting, hierarchy charts, and/or pseudocode; and the interpretation and development of record layouts, report layouts, and quality program documentation. The student becomes familiar with the syntax and logic of COBOL by coding a sequence of increasingly complex problems. The fundamental elements of batch sequential file processing are stressed, with the application of arithmetic verbs, simple and complex IF statements, EVALUATE statements, 88-levels, internal sorting, control-break processing, single-level table processing and sequential file updating.

\section{INFS3130/INFS6320 Advanced COBOL Programming ( 3 credits)}

Students are introduced Virtual Storage Access Method (VSAM). The structure and application of an EntrySequenced Data Set (ESDS), Key-Sequenced Data Set (KSDS), and Relative Record Data Set (RRDS) are presented and compared. Using the IDCAMS utility students will create and a manage VSAM clusters and datasets to support various COBOL VSAM file maintenance applications. Other course topics include advanced table processing, batch sequential file processing and updating, indexed sequential file processing and updating, random/direct file processing and the use of sub-programs. Additional concepts covered are structured program design considerations, the interrelationship of programs within an information system, coding for program efficiency and clarity, and the creation and use of quality program documentation.

\section{INFS3212/INFS6212 Enterprise Operating Systems ( 3 CREDITS )}

Using IBM mainframe hardware, operating systems and applications, this course provides an integrated view of enterprise systems. Students are provided an overview for enterprise physical and logical (LPARs) processors, I/O connectivity, DASD storage, Parallel Sysplex and clustering technologies. An overview of z/OS, z/VM, TSO/E, ISPF, zO/S Unix, datasets in a z/FS file system, JCL, and batch job entry (JES3) concepts are also presented. z/OS programming languages, CICS transaction management, DB2 database management, the z/OS HTTP web server, WebSphere Application Server, networking and security are presented from an operating system perspective. Hands-on assignments are required.

INFS3131/INFS6321 Enterprise Transaction Processing Systems using CICS/COBOL (3 CREDITS) This course focuses on the CICS Enterprise Transaction Processing System and CICS COBOL applications. CICS architecture, resource definition, CSD files and CICS tables are presented. Using a pseudo-conversational style, students will develop and test several CICS COBOL file applications using Basic Map Support (BMS) and the CICS EXEC interface. CICS Web Applications, Web Services, CICS Java Enterprise applications, and CICS security issues will be introduced.

\section{INFS4241/INFS6242 Enterprise Database Systems (3 CREDITS )}

This course focuses on the design, implementation, testing and application integration of an IBM DB2 enterprise database system. Using local client tools students will integrate the business model with logical data and physical models using a Master Data Management (MDM) approach. Using SQL DDL and DML statements students will implement tables and other structures and test the database design using interactive SQL statements and SQL code embedded in a COBOL application. Stored procedures, DB2 administration and security will be introduced. 


\section{Issues in Information Systems \\ Volume 14, Issue 1, pp.82-88, 2013}

\section{RMU Certificate Programs in Enterprise Systems}

The 18-credit, non-degree undergraduate certificate includes a total of six (6) undergraduate Computer and Information Systems (CIS) courses, and the 15-credit, non-degree graduate certificate includes a total of five (5) graduate Computer Information Systems (CIS) courses. Both programs offer students a foundation and advanced levels of COBOL Programming, Z-Operating System, Transaction Processing Systems with CICS, and database applications with DB2. All undergraduate certificate courses can then be later applied to a BS degree, and all graduate certificate courses can be later applied to a M.S. degree. While some universities offer Enterprise Systems courses in a continuing education format for their certificates, RMU decided to utilize regular undergraduate and graduate courses in the Enterprise Systems Certificate Programs.

\begin{tabular}{|c|c|}
\hline Undergraduate Certificate Enterprise Systems & Graduate Certificate Enterprise Systems \\
\hline $\begin{array}{ll}\text { - } & \text { INFS1020 Introduction to Decision Support Systems } \\
\text { - } & \text { INFS2130 Introduction to COBOL } \\
\text { - } & \text { INFS3130 Advanced COBOL Programming } \\
\text { - } & \text { INFS3131 Enterprise Transaction Processing Systems } \\
& \text { using CICS/COBOL } \\
\text { - } & \text { INFS3212 Enterprise Operating Systems } \\
\text { - } & \text { INFS4242 Enterprise Database Systems }\end{array}$ & $\begin{array}{ll}- & \text { INFS6130 Introduction to COBOL } \\
- & \text { INFS6320 Advanced COBOL Programming } \\
- & \text { INFS6321 Enterprise Transaction Processing Systems } \\
\text { - } & \text { using CICS/COBOL } \\
\text { - } & \text { INFS6212 Enterprise Operating Systems } \\
\text { INFS6242 Enterprise Database Systems }\end{array}$ \\
\hline
\end{tabular}

\section{Undergraduate Degree Programs with Enterprise Systems}

The Computer information Systems department offers five undergraduate degrees in the area of Information Systems where the 15-credit, five courses E/S Program may be easily incorporated:

1. BS Computer Information Systems (ABET Accredited)

2. BS Information Science (ABET Accredited)

3. BS Competitive Intelligence Systems

4. BS Cyber Forensics \& Information Security

5. BS Professional Communications and Information Systems.

\section{Graduate Degree Programs with Enterprise Systems}

Although each of our six MS degrees in Computing have 9 credits of electives that may be used for the Enterprise Systems courses, we have three degree programs that fully utilize the 15-credit Enterprise Systems Program:

1. MS Internet Information Systems-Concentration in Enterprise Systems degree program

2. MS Information Security \& Assurance-Concentration in Enterprise Systems degree program

3. MS Competitive Intelligence Systems-Concentration in Enterprise Systems degree program

Implementation Results from 2012-13

In the fall of 2012, the CIS Department began all Enterprise Systems instruction on the IBM mainframe, and the new $\mathrm{COBOl}$ and ZOS courses were offered for the first time. COBOL had 25 students, and ZOS has 17 students. In the spring of 2013, RMU offered COBOL, Advanced COBOL, ZOS, and the DB2 courses. COBOL had 17 students, and Advanced COBOL had 7 students. ZOS had 22 students, and DB2 had 8 students. CICS/COBOL was planned for summer 2013.

\section{Future Implementations}

Although the primary emphasis of this paper and the IBM Regional Planning Group was to focus on COBOL, other needs relating to the mainframe have become evident. In addition to the aforementioned courses, this fall (2013), Java on the Z/OS platform will be offered on-ground as well as Websphere, which is the middleware and software framework that hosts Java base web applications, will be added to the curriculum. Developing mobile applications with zEnterprise as the data source is a skilled needed by many industries and plans to introduce Worklight (the IBM 


\section{Issues in Information Systems \\ Volume 14, Issue 1, pp.82-88, 2013}

product that supports the full spectrum of mobile applications) is being considered. Finally, to support the Business Intelligence curriculum, COGNOS is being considered for implementation into the curriculum.

\section{CONCLUSIONS}

Despite what some people in the IT and computing world may contend COBOL and mainframe computers or (Enterprise Information Systems platform) has been and will continue to be an important player in the Information Technology world well into the future. The fact that there is such an immense amount of COBOL code in existence is only one of the reasons that COBOL knowledge is needed throughout the industry. There are over 200 billion lines of COBOL code with hundreds being written daily and is used to run almost three quarters of the world's business applications and powers almost all global ATM transactions [12]. Furthermore, many of those working with the COBOL language on the mainframe are reaching retirement age, and this loss creates an opportunity for universities to develop programs of instruction on enterprise mainframe systems in general and on COBOL in particular.

While other schools have begun to address the needs of Enterprise Systems instruction for COBOL, the numbers are not high. Approximately 21 universities have degree programs focusing upon Enterprise Systems. This paper focused primarily upon one University Computer and Information Systems Department where Enterprise Systems programs have been developed for use in certificates or degrees as both the undergraduate and graduate levels. COBOL, Advanced COBOL, and COBOL/CICS account for $60 \%$ of the Enterprise Systems Program.

The purpose of this program is to:

- Create strategic business partnerships with companies seeking to hire students with enterprise computing knowledge and skills.

- Build a diverse pipeline of students that have taken basic enterprise courses and who are interested in pursuing a long term career path in enterprise computing.

- Propose a school consortium that will produce a consolidated "Talent Pool" and a screened "pipeline" of Enterprise Systems candidates for regular hire and internship job opportunities.

\section{REFERENCES}

1. Anquetil, N., de Oliveira, K., M., de Sousa, K., D., \& Batista Dias, M., G. (2007). Software maintenance seen as a knowledge management issue. Information and Software Technology, 49(5), 515.

2. Bisbal,J.,Lawless, D., Wu, B., \& Grimson, J. (1999). Legacy information systems: Issues and directions. IEEE Software, 16(5), 103.

3. Gaffney,Dan.(2009). "No Respect: Survey Shows Lack of Awareness, Appreciation for COBOL". Date Retrieved March 12, 2013. http://www.reuters.com/article/2009/05/28/idUS74317+28-May2009+BW20090528.

4. IBM.(2011a).Developing Critical Thinkers --- The Key to Retaining American Industry Competitiveness. Retrieved 03/11/2013, 2013, from http://public.dhe.ibm.com/software/dw/university/systemz/CaseStudy UMarylandES.pdf

5. IBM.(2011b. More Than 1,000 Schools Help Graduates Get Jobs By Teaching the IBM System z Mainframe. Retrieved 3/05/2013, 2012, from http://www-03.ibm.com/press/us/en/pressrelease/36205.wss

6 IBM.(2011c).Transworld Data Case Study. Retrieved 03/14/2013, 2013, from http://public.dhe.ibm.com/software/dw/university/systemz/CaseStudy UniversityofArkansas.pdf

7. IBM.(2012).System z Academic Initiative program. Retrieved 3/6/2012, 2012, from http://www.ibm.com/developerworks/university/systemz/index.html

8. Micro Focus.(2007)IBM Team to Deliver Latest in Mainframe and COBOL Education Resources. (2007). Business Wire, pp. n/a-n/a. from https://reddog.rmu.edu/login?url=http://search.proquest.com/docview/445045465? accountid=28365 


\section{Issues in Information Systems}

Volume 14, Issue 1, pp.82-88, 2013

9. MicroFocus. (2012). Academic Connections. Retrieved 3/7/2012, 2012, from http://www.microfocus.com/education-services/academic/

10. Mitchell, R. (2012) Brain drain: Where Cobol systems go from here. Retrieved March 25, 2013, from http://www.computerworld.com/s/article/9225099/Cobol brain drain Survey results?taxonomyId=154\&page Number $=1$

11. Stenmark, D. (2000).Leveraging tacit organizational knowledge. Journal of Management Information Systems, 17(3), 9 .

12. Swan, G. (2009). COBOL turns 50. Retrieved March 17, 2013, from http://www.computerworld.com.au/article/319269/cobol_turns_50/. 